\title{
FORMAÇ̃̃O DOCENTE E A PERMANÊNCIA E ÊXITO NA EDUCAÇÃO PROFISSIONAL E TECNOLÓGICA
}

\author{
Eduardo do Nascimento Karasinski \\ Instituto Federal de Educação, Ciência e Tecnologia de Santa Catarina IFSC \\ DOI: 10.15628/rbept.2019.8603
}

Artigo submetido em maio/2019 e aceito em ago/2019

\section{RESUMO}

Um dos principais desafios para a EPT é atender à diversidade de público. Assim, compreender melhor os mecanismos de evasão, principalmente aqueles do âmbito de atuação docente, é importante para combater esta crítica problemática. Portanto, o objetivo deste artigo é evidenciar o alcance da relação entre ensino, pesquisa e extensão, enquanto práxis docente que alinha o conhecimento científico-tecnológico, a vivência do trabalhador e a formação docente em favorecimento da permanência e êxito discente. Para o desenvolvimento metodológico desta pesquisa foi planejado e oferecido um curso FIC em flexografia. Como ferramentas de pesquisa foram utilizados diário de campo dos docentes e relatos orais dos discentes. Analisou-se o processo de formação docente, incluindo-se o impacto da busca ativa junto às empresas sobre a permanência e êxito. A partir disso concluiu-se que, uma adequada formação docente pode ser fortemente estimulada por meio da educação não formal, disponibilizando-se espaço-tempo suficiente no planejamento do trabalho docente para encontros de grupos de estudo. A busca ativa minimizou a evasão e possibilitou um significativo engajamento dos trabalhadores, o qual foi pautado não exclusivamente na aprendizagem técnica, mas também, na relação de proximidade desenvolvida entre docente e discente.

Palavras-Chave: Formação docente. Permanência e êxito. Educação profissional. Educação não formal.

\section{TEACHER TRAINING AND STUDENT SUCCESSFUL IN THE VOCATIONAL EDUCATION}

\begin{abstract}
One of the main challenges for vocational education is to attend the different publics. Thus, a better understanding of the dropout mechanisms, especially those from the scope of teaching actuation, is important to combat this critical problematic. Therefore, the aim of this paper is to highlight the range of the relationship between teaching, research and extension as an education praxis that aligns scientific-technological knowledge, workers experience and teacher training in favor of persistence and student successful. In order to methodological development of this study was planned and offered a professional qualification course in flexography. As research tools were used field notes of teachers and oral reports of students. The process of teacher training was analyzed, including the impact of the approaching between industry and education on the persistence and student successful. From this, it was concluded that an adequate teacher training can be strongly stimulated by means nonformal education, providing sufficient space-time in the planning of teacher work for study groups. The approaching between industry and education minimized the dropout and made possible a significant engagement of the workers which was based not only on technical learning, but also on the proximity relationship between teacher and students.
\end{abstract}

Keywords: Teacher training. Persistence and student successful. Vocational education. Nonformal education. 


\section{INTRODUÇÃO}

Historicamente, a baixa frequência escolar acompanha a escola técnica, justamente por voltar-se àqueles menos favorecidos, além de outros problemas sociais persistentes envolvidos no histórico da Educação Profissional e Tecnológica (EPT) no Brasil (RODRIGUES, 2002). No estado de Santa Catarina, somente "em 2006 a problemática ganhou uma abordagem mais abrangente e sistemática através do Projeto Permanência e Êxito do Educando no CEFET-SC, [...] que tinha por objetivo estudar e organizar estratégias de combate à evasão escolar" (IFSC, 2018, p. 16). Acima disto, o Tribunal de Contas da União, por meio do acórdão no 506/2013 de 13 de março 2013, aponta índices elevados de evasão e retenção na Rede Federal de Educação Profissional e Tecnológica exigindo a implementação de planos estratégicos de enfrentamento a este problema.

Os dados colocados a seguir, apresentados por Gallindo (2018) sobre a evasão na Rede Federal de EPT, permitem caracterizar os elevados índices de evasão e retenção escolar, evidenciando uma importante problemática a ser debatida na literatura. Em média, $35 \%$ dos egressos não têm êxito na Rede Federal de EPT, enquanto que, no Instituto Federal de Santa Catarina (IFSC) este índice aumenta para $43 \%$ e, especificamente no IFSC Câmpus Caçador são $41 \%$ de egressos sem êxito no geral. Detalhadamente, as modalidades com maiores percentuais de egressos sem êxito no IFSC estão na Educação de Jovens e Adultos (EJA) e licenciaturas ambas com cerca de $64 \%$, seguido dos técnicos na forma de oferta concomitante ou subsequente, ambas com cerca de 55 \%. Os cursos de Formação Inicial e Continuada (FIC) apresentam um índice de $33 \%$ de egressos sem êxito na Rede Federal de EPT, 45 \% no IFSC e 39 \% no IFSC Câmpus Caçador. A maioria dos eixos tecnológicos no IFSC apresenta taxas de egresso sem êxito maiores do que aquelas registradas na Rede Federal, enfatizando-se aqui os eixos correlatos de Controle e Processos Industriais com 50 \% e Produção Industrial com 45 $\%$ de taxa de evasão.

Como resultado do processo de expansão e interiorização dos Institutos Federais (IFs) de Educação, Ciência e Tecnologia a partir de sua criação, houve um significativo crescimento do número de servidores, bem como, um grande aumento do número de vagas ofertadas para a modalidade EPT. Percebe-se uma relação direta entre o aumento do número de servidores e a oferta educativa, no IFSC haviam 548 docentes em 2008, aumentando para 1.283 docentes em 2016, enquanto que, eram 3.746 vagas ofertadas em 2008, passando para 26.892 vagas em 2016 (IFSC, 2017). A diversidade da oferta educativa verticalizada e, consequentemente do público atendido pelos IFs, conformam a complexidade da sua atuação, indo desde cursos de curta duração para Formação Inicial e Continuada (FIC), técnico integrado, concomitante ou subsequente, até os bacharelados, licenciaturas e pós-graduações. Atender à tamanha diversidade de público é o principal desafio em relação à capacitação dos servidores e à gestão educacional. Por isso, além de promover a ampliação do acesso e do incremento no número de vagas, também é necessário adotar ações estratégicas voltadas para a 
permanência e êxito dos estudantes, para que a instituição possa "promover a inclusão e formar cidadãos [...], gerando, difundindo e aplicando conhecimento e inovação, contribuindo para 0 desenvolvimento socioeconômico e cultural" (IFSC, 2015, p. 27).

Portanto, uma melhor compreensão de alguns mecanismos de evasão, principalmente aqueles que incluem o âmbito da atuação e capacitação docente, são de fundamental importância para o combate a esta problemática. Visto isso, este artigo apresenta os resultados parciais de uma pesquisa realizada no IFSC Câmpus Caçador sobre a oferta de curso FIC em flexografia e a sua influência no processo de qualificação de trabalhadores, tendo como objetivo central evidenciar o alcance da relação entre ensino, pesquisa e extensão, enquanto práxis docente que alinha o conhecimento científico-tecnológico, a vivência do trabalhador e a formação docente em favorecimento da permanência e êxito discente.

\section{FUNDAMENTAÇÃO TEÓRICA}

Para que o processo educacional ocorra de forma efetiva, a Lei de Diretrizes e Bases para educação nacional, estabelecidas pela Lei ํo 9.394 de 20 de dezembro de 1996, indicam como fatores a serem pensados estrategicamente: a igualdade de condição para o acesso e permanência na escola, a garantia do padrão de qualidade, a valorização do profissional da educação escolar e a vinculação entre educação escolar, trabalho e práticas sociais. A partir disso, é inevitável refletir sobre a complexidade envolvida no êxito escolar, logo que, garantir igualdade de condições à educação de qualidade para todos, numa sociedade amplamente diversificada e desigual como a brasileira, é um enorme desafio para as políticas públicas de educação. Sendo assim, é indispensável promover ações e práticas educativas contra as desigualdades social e econômica, a fim de, superar este cenário cada vez mais preocupante de baixa efetividade na educação brasileira.

A evasão escolar é um fenômeno complexo com múltiplas causas interrelacionadas, ligadas a fatores pessoais, sociais e institucionais, que podem resultar na retenção escolar, na saída provisória ou definitiva do aluno da escola. O insucesso escolar é um conceito relativo, normalmente quantificado por indicadores como taxas de retenção e abandono, mas também, a partir de outros indicadores subjetivos, como aqueles que permitem analisar o nível de adequação entre os conteúdos que são transmitidos pela escola, as exigências do mercado de trabalho e as necessidades sociais. O conceito varia em função do sistema educativo implementado, das práticas pedagógicas, das exigências curriculares e das modalidades de avaliação, em conformidade com determinado contexto. Assim, estes índices são indicadores das funções e do funcionamento do próprio sistema de educação (SIL, 2004; DORE, 2014). Além da repetência e abandono escolar, existem outros aspectos que revelam o funcionamento inadequado das instituições, tais como, a agressividade, a violência e a delinquência (CORTESẪO \& TORRES, 1990). Logo, o fracasso escolar 
traduz a falta de capacidade do sistema educativo em assegurar igualdade de oportunidades para todos a uma educação transformadora.

Entender as causas da evasão é fundamental para encontrar as soluções para o problema. Contudo, a evasão é influenciada por um conjunto de fatores que se relacionam tanto ao estudante e à sua família, quanto à escola e à comunidade da qual ele faz parte (DORE \& LÜSCHER, 2011). Uma dimensão considerada extremamente importante no estudo da evasão escolar refere-se à perspectiva familiar, o que engloba, o nível educacional dos pais, a renda familiar e a estrutura da família, por conseguinte, o capital social relacionado à família, ou seja, à qualidade das relações que os pais mantêm com os filhos, com outras famílias e com a própria escola. Isoladamente, este é o fator mais importante para o sucesso ou fracasso do estudante (DORE \& LÜSCHER, 2011 apud TEACHMAN, PEASCH \& CARVER, 1996; MCNEAL, 1999). Outro dos principais contextos de investigação do problema da evasão escolar é a perspectiva individual, que abrange os valores $\mathrm{e}$ as atitudes que promovem engajamento na aprendizagem e pertencimento social do estudante na comunidade escolar. A forma como o estudante se relaciona com essas duas dimensões da vida escolar interfere de modo decisivo sobre sua decisão em evadir ou de permanecer na escola (DORE \& LÜSCHER, 2011 apud RUMBERGER, 1995).

As causas do insucesso escolar podem estar conectadas a aspectos que evidenciam uma relação direta com o próprio aluno, tais como as capacidades, a motivação e a herança genética (FORQUIN, 1995), assim como, conectadas aos fatores sociais, uma vez que, a evasão geralmente aparece correlacionada à origem social do aluno e à sua base cultural anterior à entrada no sistema educativo (TOUTKOUSHIAN \& CURTIS, 2005). De fato, há um consenso sobre a ineficácia das interpretações centradas em uma única dimensão para situações de insucesso escolar. Neste sentido, Soares (2008) propõe um modelo conceitual que relaciona o desempenho dos alunos ligados aos fatores externos e internos da escola. O sucesso acadêmico dependerá das características das escolas, dos elementos que nela trabalham e da sua forma de organização e gestão.

$\mathrm{Na}$ perspectiva da escola, dentre os fatores que podem ser relacionados à evasão ou à permanência do estudante estão: a composição do grupo docente, os recursos didáticos disponíveis, as características estruturais da escola, os processos e práticas pedagógicas, bem como a assistência estudantil (PEREIRA \& PASSOS, 2017). Cerca de $15 \%$ da variação do rendimento escolar individual dos alunos pode estar relacionada com as características da organização do funcionamento da escola e as condições de trabalho docente (TEDDLIE \& REYNOLDS, 2000). Também há uma relação entre a desmotivação dos alunos nas aulas e a sua retenção ou evasão de acordo com as práticas pedagógicas utilizadas pelos professores em sala.

A formação de turmas com alunos sem qualquer orientação profissional para determinadas áreas de formação, incluindo as práticas disciplinares tradicionais, com o seu sistema de avaliação essencialmente sumativa e centrada quase exclusivamente na aquisição dos conteúdos, são causas pedagógicas que promovem 
o insucesso e o abandono dos alunos, majoritariamente com alunos de origem em famílias com baixas expectativas em relação à escola e ao futuro dos seus educandos. [...] Os professores consideram que adaptar o estilo e o método de ensino à diversidade desses alunos, significativamente marcados pelo insucesso escolar, é uma tarefa difícil, que não favorece os alunos com maior risco de insucesso. [...] Os conhecimentos prévios dos alunos, assim como, a desmotivação pela escola e o desinteresse pelos conteúdos mais acadêmicos do currículo, são causas consideradas relevantes pelos professores e pelos próprios alunos para a retenção e o abandono. Consideram ainda que, é difícil recuperar e motivar alunos que acedem a cursos com graves carências nos seus conhecimentos, considerados pré-requisitos fundamentais de acesso (PINTO, DELGADO \& MARTINS, 2015, p. 17-18).

Nesta citação deve-se destacar que um aspecto empírico presente nas falas dos professores que atuam em sala de aula é que os conhecimentos prévios do aluno predizem o êxito ao longo dos anos escolares, porque condicionam os níveis de atenção, percepção, compreensão e organização das informações obtidas.

Considerando a grande heterogeneidade social, cultural, de capacidades e de motivação dos alunos que acessam o ensino profissional, é fundamental que a preparação dos professores que lecionam nessa modalidade de ensino não esteja centrada exclusivamente no domínio do âmbito científico-tecnológico. Além de obter conhecimentos didáticos, práticas pedagógicas da implementação e da articulação da estrutura curricular, domínio de estratégias de motivação dos alunos para a participação nos processos de ensino e de avaliação, também é importante compreender os interesses profissionais dos alunos e o contexto no qual ele está inserido. Diante disso, é preciso compreender as demandas colocadas para a Educação Profissional e Tecnológica (EPT) e as respostas que ela pode dar, tanto no sentido de uma educação para o sistema capitalista e, portanto, para consolidar a sua hegemonia, quanto uma educação emancipatória para o trabalhador e, por conseguinte, instrumento de contra-hegemonia (CARVALHO, 2003). O trabalho, enquanto valor social, é um princípio educativo fundamental. Todavia, o trabalho, como valor de troca sob as relações capitalistas é, para a grande massa de trabalhadores, um processo alienador (FRIGOTTO, 1996). É preciso compreender a política pública profissional no contexto capitalista, almejando a ampliação dos níveis de escolarização formal aos trabalhadores, e assim, a democratização do conhecimento às classes trabalhadoras, concebendo o trabalho numa perspectiva de humanização (KUENZER, 2010).

A EPT abrange processos educativos para a aplicação, adaptação e geração tecnológica, de grande importância para o desenvolvimento e 0 atendimento das demandas socioeconômicas regionais, requerendo uma formação docente adequada à atual complexidade do mundo do trabalho. Os professores da EPT enfrentam desafios relacionados às mudanças organizacionais que afetam as interrelações profissionais, aos efeitos das inovações tecnológicas sobre as atividades de trabalho, ao aumento das exigências de qualidade e flexibilização na produção e nos serviços e à exigência de maior atenção às questões éticas e de sustentabilidade (MOURA, 2008). 
O perfil do docente da educação profissional precisa dar conta de três níveis de complexidade: i) desenvolver capacidades de usar, nível mais elementar relacionado à aplicação dos conhecimentos e ao emprego de habilidades instrumentais; ii) desenvolver capacidades de produzir, que requer o uso de conhecimentos e habilidades necessários à concepção e execução de objetivos para os quais as soluções tecnológicas existem e devem ser adaptadas; e iii) desenvolver capacidades de inovar, nível mais elevado de complexidade relacionado às exigências do processo de geração de novos conhecimentos e novas soluções tecnológicas (MACHADO, 2008, p. 18).

Alcançar esse patamar diferenciado de educação, voltado para o mundo do trabalho, inicia-se pela formação e adesão do professor. A reestruturação dos saberes docentes exigem análise, reflexão e intervenção críticas e criativas sobre as suas atividades, tendo em conta que:

a) a realidade é uma totalidade em que estão presentes os aspectos econômicos, políticos, históricos, culturais, científicos, tecnológicos, ambientais; b) o ser humano atua sobre a natureza e sobre a sociedade a que pertence em situação social e não apenas individual; c) é nesse processo que ocorre a objetivação de bens, produtos e serviços e a subjetivação do próprio produtor; d) a aprendizagem significativa supõe que os conteúdos devem ser contextualizados e a realidade deve ser pensada criticamente além do senso comum; e) a simples opção metodológica não dá conta de todas as implicações históricas e epistemológicas do conhecimento secularmente acumulado pela humanidade; f) na educação ocorre um processo contínuo de apropriação, objetivação e subjetivação dos conteúdos disciplinares em relação íntima com os métodos e processos utilizados (FRANCO, 2008, p. 50).

De acordo com Arroyo (2003), é necessário reconhecer que sem propostas práticas de articulação entre educação profissional e educação básica, os jovens não conseguem compreender as mudanças da economia e da sociedade, tão pouco participar criticamente dessas mudanças. Isso implica em educação profissional integrada à educação básica. Outro elemento tão necessário quanto, é a formação continuada dos professores, haja vista as transformações nas relações de trabalho na sociedade atual. A relação da prática docente com os seus saberes não se reduz a uma simples função de transmissão. "Define-se o saber docente como um saber plural, formado de saberes oriundos da formação profissional e de saberes disciplinares, curriculares e experimentais" (TARDIF, 2014, p. 36).

A formação continuada docente compreende dimensões coletivas, organizacionais e profissionais, bem como, o repensar do processo pedagógico, dos saberes e valores, e envolve atividades de extensão, grupos de estudos, reuniões pedagógicas, cursos, programas e ações para além da formação mínima exigida ao exercício do magistério da educação básica, tendo como principal finalidade a reflexão sobre a prática educacional e a busca de aperfeiçoamento técnico, pedagógico, ético e político do profissional docente (Parecer CNE/CP 02/2015, 2015, p. 34).

O docente da EPT deve ter um perfil ancorado, sobretudo, no trabalho coletivo e interdisciplinar. É um pressuposto básico que estes profissionais tenham uma perspectiva crítica e reflexiva, assumindo a tecnologia orientada para a responsabilidade social (MOURA, GARCIA \& 
RAMOS, 2007). Deste modo, "se a prática docente é um processo constante de estudo, de reflexão, de discussão, de experimentação conjunta e dialética entre o grupo de professores, se aproximará da tendência crítica, assumindo um determinado grau de domínio de si mesmo" (IMBERNÓN, 2011, p. 36).

Um dos desafios para a formação dos professores para a EPT está em motivar-Ihes a investigar os saberes próprios do ensino, sendo necessário para isso, a produção de estudos que consigam revelar as singularidades do contexto complexo de trabalho no qual esses professores encontram-se mergulhados (GARIGLIO \& BURNIER, 2012). O sujeito gerador de conhecimento, na medida em que, pesquisa a própria atuação e de outros docentes, se reconhece como partícipe de uma comunidade profissional, ao mesmo tempo em que se forma como profissional. Somente a partir deste ponto, o professor tem plenas capacidades de conduzir seus alunos na direção da autonomia e da inovação. A pesquisa como princípio educativo colabora para edificar a autonomia dos indivíduos, porque desenvolve a capacidade de aprender a aprender, logo que, o sujeito deixa de ser um depósito de conhecimentos e passa a desconstruir e reconstruir suas próprias convicções a respeito da ciência, da tecnologia e da sociedade. Segundo Moura (2008, p. 36), "é preciso compreender o estudante como ativo no processo de ensino-aprendizagem, capaz de construir seu próprio conhecimento e, assim, assumir a capacidade de pensar sobre sua própria formação". O desafio da promoção da autonomia discente perpassa pela compreensão de metodologias capazes de inserir "atividades que permitem a imersão no mundo do trabalho, tal como a pesquisa de campo ou experimental e os projetos de extensão, que podem viabilizar uma relação práxica com a área de trabalho que fundamente o trabalho pedagógico" (KUENZER, 2010, p. 506).

Dentre outras dificuldades que afloram nas escolas, merecem destaque as questões relacionadas aos investimentos, à gestão democrática, à falta de profissionais da educação e, principalmente, à sua baixa valorização (MOURA, 2008). "Uma política de formação de professores só tem sentido quando integrada à estruturação da carreira docente, à política salarial que assegure a dignidade do professor e à garantia de condições adequadas de trabalho" (KUENZER, 2011, p. 4). Conforme apontado por Saviani (2011), é impossível equacionar o problema da formação de professores sem enfrentar simultaneamente a questão das condições do trabalho docente, pois estes aspectos andam juntos. A relação entre uma adequada formação e o exercício do trabalho satisfatório está diretamente associada à valorização do magistério. Por fim, sugere-se que, os esforços para a formação docente só serão significativos no contexto de sala de aula se,

existirem melhores condições de trabalho, nomeadamente a existência de um reduzido número de alunos por turma para o desenvolvimento de aulas mais experimentais e práticas, mais tempo disponível para o trabalho dos professores em equipe através de uma nova organização dos horários e dos espaços, o desdobramento das áreas curriculares com mais tempo destinado às aulas práticas e uma atenção mais individualizada aos alunos marcados pelo insucesso (PINTO, DELGADO \& MARTINS, 2015, p. 19). 
Considerando as premissas apresentadas enquanto norteadoras da discussão a ser apreciada neste artigo, o mesmo visa compreender como fatores de integração da educação profissional com a educação básica e o trabalho docente podem auxiliar na reflexão acerca da permanência e êxito nos cursos de qualificação profissional, tendo como exemplo o curso FIC em flexografia ministrado no IFSC Câmpus Caçador.

\section{PROCEDIMENTOS METODOLÓGICOS}

Este é um trabalho de pesquisa qualitativa quanto à abordagem e de caráter exploratório quanto aos objetivos (GERHARDT \& SILVEIRA, 2009), o qual foi planejado metodologicamente com base na indissociabilidade entre ensino, pesquisa e extensão. Para atender o eixo do ensino ofertou-se um curso de qualificação profissional em flexografia na modalidade de Formação Inicial e Continuada (FIC). A flexografia é um método de impressão rotativa direta que utiliza placas resilientes que transferem uma tinta fluida de secagem rápida para a superfície do filme plástico para fabricação de embalagens (SCARPETA, 2007). Este processo depende de muitas variáveis e exige uma fundamentação científica adequada dos profissionais da área. $\mathrm{O}$ profissional que trabalha na área de flexografia utiliza diversos conceitos específicos no seu dia a dia e carece de conhecimentos científicos aprofundados. Devido à complexidade técnico-científica envolvida, aplicou-se métodos de ensino que visam a reflexão e a autonomia individual, a partir do pensamento crítico no qual se estabelece cinco níveis, que são respectivamente identificação, definição, exploração, aplicabilidade e integração de uma problemática (GIANNASI \& BERBEL, 1998). O pensamento crítico demanda compreensão de questões complexas e informações associadas com um problema. É um processo de dar sentido às experiências externas através de análises das questões e informações. Portanto, aplicou-se métodos de resolução de problemas e análise de conteúdo com o suporte de uma problematização.

A proposta didático-pedagógica para a oferta da formação inicial e continuada foi realizada de maneira interdisciplinar (FAZENDA, 2008) e com uma equipe multidisciplinar visando uma formação integral do trabalhador (SANTOMÉ, 1998; RAMOS, FRIGOTTO \& CIAVATTA, 2005). Dividiram-se os conteúdos em 3 blocos. O primeiro bloco com o total de $60 \mathrm{~h}$ de conteúdos específicos da flexografia, enfatizou-se o caráter teórico, como por exemplo, produção da arte gráfica ou conceitos sobre viscosidade da tinta, dentre outros. No segundo bloco com o total de $60 \mathrm{~h}$ focou-se no caráter prático, como por exemplo, montagem do clichê ou ajuste da impressora flexográfica, dentre outros. O último bloco com total de $40 \mathrm{~h}$ foram selecionados conteúdos relativos a trabalho e sociedade, como organização dos trabalhadores ou sustentabilidade, dentre outros. A execução cronológica da sequência didática de conteúdos não ocorreu em forma de blocos. Ela foi administrada de maneira interdisciplinar, alternando as aulas teórico-práticas da área específica com aulas compartilhadas entre professores de diferentes áreas abordando temas comuns, como por exemplo, comunicação técnica com 
aspectos visuais da arte gráfica ou saúde e segurança no trabalho com produtos orgânicos voláteis, dentre outros. Ao todo participaram do curso professores das áreas de engenharia de materiais, química, português, artes visuais, geografia e sociologia.

Realizou-se extensão através da atuação no ambiente de trabalho, aproximação com as empresas e com o protagonismo dos trabalhadoresestudantes. Foi proporcionado um seminário de abertura sobre flexografia com palestras de técnicos da área em parceria com uma empresa local. Sobretudo, os alunos puderam realizar atividades de aprendizado nesta mesma empresa parceira, como o ajuste dos equipamentos e a medição da cor, além de, visitas técnicas em outras 3 empresas do ramo. Articulou-se a oferta da formação com a empresa parceira, a qual ofereceu transporte e saída antecipada em $1 \mathrm{~h}$ do expediente de trabalho como incentivos aos funcionários para a participação no curso. Adicionalmente, realizou-se 3 visitas pelos professores às empresas para articulação de estratégias motivacionais e compreensão do ambiente de trabalho pelos docentes. Todas estas ações voltadas para atividades de extensão, englobam aspectos do processo o qual definimos aqui como: busca ativa.

Ofertaram-se duas turmas do curso FIC em flexografia com 25 vagas tanto no primeiro semestre de 2017, quanto no segundo semestre de 2017. Para fins comparativos, com a turma do primeiro semestre foi realizada a busca ativa, porém, com a turma do segundo semestre não foi realizado o processo da busca ativa. Portanto, a articulação da oferta deu-se somente por meio da divulgação regular realizada pelo departamento responsável no IFSC Câmpus Caçador.

Para atender o eixo da pesquisa, utilizou-se como ferramenta para coleta de dados diário de campo, (EMERSON, FRETZ \& SHAW, 1995) escrito por todos os professores participantes após cada aula ministrada. Voltar-se para as atividades didáticas reflete os aspectos significativos do ensino e aprendizagem procurando estabelecer uma ligação entre a teoria e a prática educacional (VIANNA, 2003). Também utilizou-se relatos orais dos discentes por meio de vídeos sobre a sua rotina profissional durante o curso, as suas impressões das práticas pedagógicas e a aprendizagem nas aulas.

\section{RESULTADOS E DISCUSSÃO}

A partir das estratégias traçadas para conciliar ensino, pesquisa e extensão, analisou-se o diário de campo dos professores para a reflexão sobre a prática docente após a oferta do curso FIC em flexografia. Este artigo, limita-se a análise dos aspectos que envolvem a formação docente e a permanência e êxito. Os aspectos didáticos-pedagógicos e o contexto regional desta pesquisa foram previamente publicados em outro trabalho (NASCIMENTO, et al, 2018). Por isso cabe destacar que, os professores relataram em seus manuscritos a influência fundamental que o processo de estudos em grupo teve sobre a organização pedagógica do curso e, principalmente, para a formação docente. Um breve relato sobre o grupo de 
estudos em educação no IFSC Câmpus Caçador precisa ser introduzido, a fim de localizar o leitor com a relação a este aspecto.

O grupo de estudos em educação foi criado em 2016 por professores recém-chegados à instituição, motivados pelas novas possibilidades profissionais e, portanto, com objetivos comuns com respeito à docência. $\mathrm{O}$ objetivo do grupo era realizar leituras e debates semanais de textos indicados pelos participantes sobre temas na área da educação. Em primeiro momento discutiu-se sobre educação integral e educação profissional, perpassando por temas como interdisciplinaridade, pesquisa como princípio educativo, politecnia, legislações, pedagogia crítica, projeto político pedagógico, projeto pedagógico de curso, entre outros. No final de 2016, o grupo planejou a proposta metodológica para este projeto, então, executou-a no ano seguinte. Concomitantemente, o grupo de estudos manteve-se, dentre outras discussões, analisando as observações em relação ao andamento do FIC ofertado. Este processo cooperativo de construção do conhecimento foi a base para a capacitação focada ao ensino profissional dos docentes envolvidos.

Retomando a relação entre a formação docente e o mundo do trabalho, nas últimas décadas, devido às mudanças na economia, na sociedade e no mundo do trabalho decorrentes dos novos paradigmas do sistema de acumulação flexível, passaram-se a valorizar processos de aprendizagem em grupos e a dar-se importância aos valores culturais, os quais articulam as ações dos indivíduos para desenvolverem objetivos comuns de forma não institucionalizada. Isto abrange uma visão ampla da educação, utilizando esforços para universalização do conhecimento e inovações dos meios existentes de aquisição dos mesmos. Esta visão ampla de educação passa a incorporar ideias sobre a educação não formal. Assim, define-se a educação não formal sob quatro dimensões de abrangência.

A primeira envolve a aprendizagem política dos direitos dos indivíduos enquanto cidadãos, isto é, o processo que gera a conscientização dos indivíduos para a compreensão de seus interesses, do meio social e da natureza que o cerca, por meio da participação em atividades grupais. Segundo, a capacitação dos indivíduos para o trabalho, por meio da aprendizagem de habilidades e desenvolvimento de potencialidades. Terceiro, a aprendizagem e o exercício de práticas que capacitem os indivíduos a se organizarem com objetivos comunitários, voltadas para a solução de problemas coletivos cotidianos. A quarta é a aprendizagem dos conteúdos da educação formal, escolar, em formas e espaços diferenciados. [...] A educação transmitida pelos pais na família, no convívio social são considerados educação informal. O que diferencia a educação não formal da informal é que na primeira existe a intencionalidade de dados sujeitos em criar ou buscar determinadas qualidades ou objetivos. Enquanto que, a educação informal decorre de processos espontâneos. A educação não formal são ações e práticas coletivas organizadas em movimentos, organizações e associações sociais. [...] As categorias de espaço e tempo têm novos elementos na educação não formal, porque usualmente o tempo de aprendizagem não é fixado e são respeitadas as diferenças existentes para a absorção e reelaboração dos conteúdos, implícitos ou explícitos, no processo de ensino-aprendizagem. Como existe a flexibilidade no 
estabelecimento dos conteúdos, segundo os objetivos do grupo, a forma de operacionalizar estes conteúdos têm diferentes dimensões em termos de sua operacionalização. Assim, o espaço também é algo criado e recriado segundo os modos de ação previstos nos objetivos maiores que dão sentido ao fato de determinado grupo social estar reunido (GOHN, 2011, p. 106-108).

A Resolução CNE/CEB no 06/2012 define diretrizes curriculares nacionais para a EPT de nível médio. Baseado em tal resolução de caráter regulatório, oportuniza-se até 2020 algumas possibilidades de formação inicial para docência na EPT aos profissionais não licenciados. Estas podem se dar através de cursos de graduação e programas de licenciatura, por reconhecimentos de saberes profissionais em processos destinados à formação pedagógica ou à certificação da experiência docente e na forma de pós-graduação lato sensu.

Novamente, um breve relato de experiência colocado a seguir, fornece argumentos importantes para a discussão aqui proposta. $O$ docente engenheiro de materiais, formação cujos conhecimentos não incluem a formação pedagógica, adquiriu tais conhecimentos por meio dos estudos e da integração com profissionais de diferentes áreas do conhecimento no grupo de estudos, empoderando-se com criticidade para pesquisar a própria prática docente. Este processo de capacitação não formal foi indispensável para o modo de organização das aulas ministradas. As atividades do grupo de estudo e a interação entre os seus participantes possibilitou uma formação adequada, muito semelhante à estrutura curricular de cursos formais de especialização pedagógica para a EPT, pois, reuniu os estudos e debates de conteúdos importantes da literatura da educação, combinado a prática docente e a reflexão sobre o contexto da sua atuação. Este processo não formal de capacitação docente por meio do grupo de estudos foi posto à prova, no sentido que, o mesmo docente engenheiro de materiais, ingressou no segundo semestre de 2017 no curso de especialização em EPT ofertado na modalidade à distância pelo Centro de Referência em Formação e Educação à Distância do IFSC. No relato do determinado professor consta que, muitas das atividades avaliativas da especialização cursada, puderam ser realizadas indissociavelmente das aulas ministradas no FIC em flexografia e em outros cursos que o docente atuou. Por exemplo, a citação do diário de campo: "as anotações da aula sobre problemas de impressão relacionados à viscosidade da tinta resultaram na avaliação da disciplina da especialização sobre Didática na Educação Profissional, realizada antes mesmo dessa atividade sobre elaboração de um experimento ter sido proposta" (professor A). Dentre outras atividades pedagógicas que puderam ser incluídas em disciplinas como Pesquisa e Extensão como Princípios Educativos na Educação Profissional, mais um relato de experiência é pertinente aqui. $O$ relatório de intervenção de prática docente proposto como atividade avaliativa da disciplina sobre Prática Docente, foi baseado nas atividades concomitantemente desenvolvidas no curso técnico em plásticos durante o projeto integrador, cuja proposta metodológica também foi construída coletivamente dentro do grupo de estudos.

É importante salientar que, o debate da literatura em função da formação docente, assim como as estratégias de gestão educacional, não 
valorizam a educação não formal e o seu impacto na melhoria das atividades pedagógicas no ensino profissional, algo percebido e posto como foco central desta discussão. Propõe-se que, a capacitação por meios não formais de educação, é uma maneira fortemente eficaz para a solução da problemática que envolve a formação docente para a EPT, a qual não tem sido considerada. As vantagens são enormes, levando em consideração a possibilidade de personalização dos saberes a serem aprendidos, selecionados pelos docentes em convergência com o seu contexto específico de atuação. Além disso, deve-se considerar a maior interação e a intensa troca de conhecimento entre o grupo docente, fortalecendo as práticas pedagógicas colaborativas e interdisciplinares, proporcionando a reflexão sobre a prática docente e a geração de conhecimentos, patamar fundamental para a educação crítica e emancipadora. Como citado por Gohn (2011, p. 110), "na educação não formal a cidadania é o objetivo principal, ela é pensada em termos coletivos por meio da prática social [...]. É a experiência das pessoas em trabalhos coletivos que gera o aprendizado."

Uma revisão de trabalhos recentes da literatura reforçam as dificuldades encontradas com relação à formação docente. Os recortes apresentados a seguir corroboram os aspectos ressaltados anteriormente acerca do impacto do processo não formal de capacitação para EPT.

\begin{abstract}
Urge por um momento de formação, na qual se articule formação específica e formação geral. Mas não somente um momento fragmentado de capacitação, e sim, um que integre formação contínua de troca de conhecimentos e reflexão sobre a prática dos docentes. Por outro lado, consideramos fundamental que essa formação também seja iniciativa do próprio profissional. [...] Sendo assim, de acordo com a fala dos docentes, no transcorrer da pesquisa, inferimos que o professor que atua na educação profissional tem sua prática dificultada, por, na maioria das vezes, não conseguir articular conhecimentos gerais e específicos à educação profissional e, possivelmente, por não entender quais os saberes necessários para atuação na educação profissional, além de dar mais importância a um saber que outro, quando na verdade, estes saberes devem estar associados às diferentes áreas, impulsionados por sua ação-reflexão-ação (FONSECA, 2017, p. 174-176).
\end{abstract}

Outros trabalhos (SANTOS, AZEVEDO \& GONZAGA, 2015; CAMPOS, et al, 2015; TAVARES \& GONZAGA, 2016; HENRIQUE, et al, 2017) também mostram que a separação entre o ensino básico e profissional é um problema pertinente na educação profissional. Exemplificando esta questão, é notável o apontamento dos autores sobre as dificuldades de apropriação epistemológica das concepções de formação integral e formação integrada presente nos Projetos Pedagógicos dos Cursos, oriunda do percurso formativo dos docentes que não possuem formação específica ou formação didático-pedagógica. Estes têm a tendência a desarticular teoria e prática, saberes técnicos e básicos, colocando-os em patamares dicotômicos e hierarquizados que dificultam a ação-reflexão-ação em sua práxis de sala de aula, impactando na permanência e êxito discente. Nesse sentido, há um desafio para a formação docente em superar a barreira histórica construída na educação básica e profissional. Da Silva, Queiroz e Medeiros (2017, p. 80) constatam que os docentes bacharéis pesquisados "não entendem o trabalho 
enquanto princípio educativo, mas, associando ao campo da Educação Profissional, como mero ensino voltado para a preparação, ou capacitação para o mercado de trabalho". Na pesquisa publicada por Vieira, Vieira e Pasqualli (2014, p. 49) as "falas dos docentes revelam o modelo da racionalidade técnica que compreende a educação como uma ciência aplicada, restringe a atuação do professor a um técnico que, com base num conjunto de prescrições recebidas em seu curso de formação, desenvolve sua atividade profissional com a aplicação de teorias e técnicas." Por outro lado, e mesmo contraditoriamente, apesar dos professores da EPT não licenciados terem experiências desafiadoras pela ausência de conhecimentos pedagógicos, a partir da formação pedagógica inicial,

\begin{abstract}
reconhecem a necessidade dessa formação para o exercício da docência e, ainda, da preparação para a profissão, que se dá por meio de integração com os demais colegas, por influência das experiências acadêmicas, pessoais e práticas vivenciadas, e por meio de estudos. [...] Porém, alguns apresentam resistência no aceite das contribuições dos fundamentos pedagógicos para a prática docente, mas, ao mesmo tempo, mostram-se preocupados com a formação integral do estudante, quando se interessa por sua realidade e com sua aprendizagem, por meio de aplicação de novas metodologias e adequação de conteúdos. [...] Pode-se constatar nos relatos, ainda, ênfase no saber experiencial para a docência, que por sua vez contribui com a construção do saber pedagógico, já que os valores, crenças e saberes desenvolvidos a partir de sua história de vida são agregados e aplicados na docência, servindo de reflexão e construção da própria prática, quando apontam que reproduzem práticas pedagógicas positivas de seus antigos docentes (RODRIGUES \& FREITAS, 2016, p. 68).
\end{abstract}

A literatura sobre formação docente é enfática em pontuar que 0 saber docente é construído continuamente pelo professor, que consciente de sua ação por meio da perspectiva crítico-reflexiva que edifica sua própria formação. Corrobora Nóvoa (1991, p. 13), "a formação não se constrói por acumulação de cursos, de conhecimentos ou de técnicas, mas sim através de um trabalho de reflexividade crítica sobre as práticas e de reconstrução permanente de uma identidade pessoal". Nascimento, Souza e Oliveira (2018) discutem a relação entre as mudanças de paradigmas na EPT como mudanças de concepção de mundo, trazendo um debate importante sobre revolução científica. Destacam que os atuais paradigmas da educação, já não são capazes de solucionar os problemas da sociedade. Em confronto a isto, os avanços científicos e tecnológicos, precisam estar aliados ao progresso humano, ético e social por meio da educação. A discussão aponta para a compreensão de que a mudança desses paradigmas na educação tecnológica, levarão a uma percepção de mundo distinta, tendo em vista a insuficiência de ações inovadoras que aumentem o debate sobre mudanças de paradigmas na educação e as consequências para a EPT. Torres, Silva e Alves (2017) escrevem na mesma linha de pensamento, relatando que é necessário preocupar-se com mudanças em determinados modelos nas instituições, principalmente com relação a formação inicial e continuada de professores, para que os mesmos possam compreender a ciência, tecnologia e sociedade para além do viés positivista que permanece impregnado nos sistemas educativos, limitados a algumas áreas do saber. A ciência e a tecnologia devem permear e dialogar sobre todas as áreas do conhecimento, 
de maneira que, essa inserção atue na construção de um novo projeto para a EPT, pautado numa formação competente, ética, integral e humana. Nesse caso, percebe-se que o docente deve buscar determinadas mudanças, pois é um processo em permanente construção.

Bazzo (2015), faz uma reflexão sobre o ensino tecnológico, abordando algumas estratégias que ajudam na implementação de conteúdos e na formação docente, refletindo diretamente no processo de ensinoaprendizagem. Segundo o autor, a criação de grupos de estudos permanentes pode propiciar um fórum de debates acerca de questões relacionadas à EPT. Este seria um caminho para a criação de alternativas de implementação de novas políticas de ensino-aprendizagem. Motta, Cavalcante e Lemos, (2018) relataram a experiência de 4 anos de desenvolvimento de projetos de extensão e pesquisa, mostrando que os projetos não só ajudaram na identificação das demandas de formação, mas colaboraram com a capacitação dos docentes no uso das tecnologias educacionais. Porém, concluem que, ainda não há oferta suficiente de formação continuada por meio da extensão para adequação das práticas pedagógicas dos docentes. Diante disso, os autores ratificam que, a hiperburocratização é desafiadora do trabalho escolar e das crescentes demandas de produtividade sobre professores e estudantes. Isto é, grande parte das práticas extensionistas das instituições públicas de ensino são reguladas pelo tempo institucional, dependem do calendário letivo, de editais de apoio, de carga horária de trabalho dos profissionais e vinculação acadêmica nos cursos de formação profissional. Ainda assim, as práticas extensionistas fundamentadas detêm uma alta possibilidade de efetiva capacitação profissional e de transformação dos partícipes.

Insere-se aqui que, a adequação do desempenho docente pode ser estimulada por meio da educação não formal, incentivando-se e disponibilizando-se espaço suficiente no planejamento do trabalho docente para encontros de grupos de estudo e grupos de pesquisa, para que os professores, de acordo com seu perfil de competências e objetivos comuns, discutam a sua prática constantemente. Isto fornece possibilidades para refletir sobre suas ações e construir conhecimentos e técnicas próprias, levando a um ajuste entre as atividades docentes e a realidade local. Este caminho alternativo de formação docente precisa ser aprimorado e implementado, de maneira que, as possibilidades para a formação docente sejam ampliadas.

Iniciativas que referem-se à formação docente continuada são bastante importantes para a diminuição da evasão e da retenção, visto que, são essenciais do caráter preventivo desta problemática (SILVEIRA, GONÇALVES \& MARASCHIN, 2017). Para abordar a estreita relação na qual a formação docente faz com o êxito discente, analisou-se o processo de busca ativa, definida como o conjunto de várias ações de aproximação com os profissionais e empresas que atuam na área do respectivo curso, neste caso, a flexografia. No final do segundo semestre de 2016 realizou-se um seminário de flexografia no IFSC Caçador com uma empresa parceira. Cerca de 100 pessoas que trabalham no segmento de flexografia participaram de uma tarde de palestras com assistentes técnicos de vários fornecedores de 
insumos e equipamentos para flexografia. Neste mesmo dia o curso de flexografia foi anunciado gerando expectativas de qualificação para tais trabalhadores. Este foi o início da aproximação com o respectivo público-alvo.

Paralelamente ao planejamento do FIC em flexografia, os professores realizaram visitas às empresas locais. Nestas visitas, foi possível conhecer com maior profundidade as dificuldades e a organização das rotinas dessas empresas. Esta iniciativa faz parte do processo de formação docente não formal. Se, o professor bacharel citado anteriormente teve como base os conteúdos pedagógicos estudados em grupo, por outro lado, os professores licenciados da formação propedêutica também se capacitaram através destas visitas técnicas. Estes professores relataram um ganho de experiência bastante relevante acerca da rotina técnica e do ambiente de trabalho industrial, mudando o seu jeito de pensar o ensino profissional. Antes disso, não tinham a noção real do cotidiano dos trabalhadores estudantes, não sabiam das suas práticas, menos ainda, das condições disponíveis para exercício da atividade laboral. O contato direto com áreas fora de seu âmbito de conhecimento formal, os capacitou a direcionar e preparar aulas voltadas à realidade enfrentada pelos alunos. Esta outra forma de capacitação docente foi igualmente importante para a estruturação pedagógica do curso ofertado. Desde os conteúdos, até os horários do curso foram construídos de acordo com as condições de contorno das empresas, e consequentemente, das necessidades dos trabalhadores.

Junto do processo de formação docente, houve uma aproximação entre a escola e as empresas, fazendo com que os trabalhadores tivessem maior acesso à instituição educacional, neste caso o IFSC. Através desta aproximação, as empresas também auxiliaram e incentivaram seus funcionários a qualificar-se, atuando como uma importante estratégia motivacional de permanência. Fizeram a divulgação do curso, indicaram trabalhadores e a empresa parceira forneceu transporte e $1 \mathrm{~h}$ do horário de trabalho para que os trabalhadores que participaram do curso pudessem se preparar para as aulas.

O resultado do processo de busca ativa pode ser observado por meio da análise dos ingressos no FIC do primeiro semestre de 2017. Inscreveramse 57 candidatos para uma turma com 25 vagas, sendo que, foram 21 egressos com êxito. Este é um resultado extremamente positivo para o combate à evasão, haja vista, os alarmantes índices de evasão no IFSC. Dos alunos evadidos, 2 tiveram problemas pessoais que não quiseram revelar e desistiram logo no início do curso. 1 aluno haitiano desistiu devido à distância de sua residência e dificuldades com o transporte público estando ele desempregado. 1 aluno desistiu por problemas de saúde na família, o impossibilitando de frequentar as aulas. As causas destas poucas desistências são incontroláveis e dependem de uma conjuntura maior que as atribuições e possibilidades de influência da escola ou dos professores, que muitas vezes não conseguem abarcar.

$O$ resultado torna-se ainda mais significativo ao analisar-se o perfil desta primeira turma. Devido ao processo de busca ativa, exceto um dos alunos, os demais que frequentaram o curso faziam parte do público-alvo, ou seja, trabalhavam em empresas locais da área de flexografia. A maioria dos 
alunos tinham experiência, atuando em média a 5 anos no ramo. Alguns dos alunos possuíam até 14 anos de experiência na flexografia e trabalhavam como líderes nas suas respectivas empresas. A busca ativa possibilitou um forte engajamento destes profissionais no curso FIC, que foi pautado não exclusivamente nos conhecimentos técnicos, mas também, na relação de proximidade desenvolvida entre os docentes, os trabalhadores e as instituições. Num depoimento gravado por um dos alunos, fica claro a importância das relações interpessoais no processo de educação dos trabalhadores. O aluno A declarou: "pra mim o que teve de diferente aqui foi a união nossa, dos nossos colegas."

O empoderamento dos estudantes durante as aulas, aproveitando suas experiências anteriores, foi um aspecto fundamental para gerar um ambiente amistoso e colaborativo entre os alunos e professores. De acordo com os manuscritos dos diários de campos, o professor que lecionou a parte técnica aos alunos aprendeu mais sobre flexografia do que ensinou durante o curso. A troca de conhecimentos entre alunos e professores é um fator essencial tanto para a formação docente, quanto para o empoderamento e, consequentemente, permanência e êxito escolar destes trabalhadores. Cada um dos envolvidos pode colaborar com suas experiências específicas contribuindo bastante para o aprendizado coletivo. Por isso, mesmo os alunos com maior experiência, assimilaram novos saberes do curso, como observado em outro trecho dos depoimentos, "a gente nunca sabe tudo, o conhecimento dos professores é enorme e com as conversas durante as aulas a gente sempre aprende um pouco mais" (aluno B). A partir dos relatos orais dos discentes gravados em vídeo, ficou evidente a influência que o curso trouxe para a atividade laboral deles, tanto em relação às novas tecnologias, quanto em relação aos conhecimentos para a formação cidadã.

$\mathrm{Na}$ segunda turma ofertada no segundo semestre de 2017, não foi realizado o processo de busca ativa para fins comparativos. Desta maneira, a divulgação ao público-alvo foi realizada somente pelos meios institucionais. As diferenças em relação aos números que balizam a permanência e êxito são enormes. Nesta segunda turma, inscreveram-se somente 18 candidatos não completando o número de vagas disponíveis. Sobretudo, matricularam-se 13 alunos, dos quais após a segunda semana de aulas, restaram 9 estudantes frequentando o curso. Ao final concluíram o curso com êxito 7 estudantes. Ao analisar o perfil da turma, novamente as diferenças com a primeira turma ofertada são grandes. Dos 13 estudantes matriculados, apenas 4 trabalhavam na área da flexografia, isto é, configuram-se como público-alvo. Apesar de, a proposta pedagógica de o curso ser a mesma da anterior com pequenas correções metodológicas, a evasão bateu os índices atuais para esta modalidade. Como não se tinha estabelecido a busca ativa, não foi possível saber os motivos de evasão. Por conseguinte, constata-se que este processo de busca ativa é um fator de grande influência na permanência e êxito. Este processo deve fazer parte do trabalho docente, cabendo também para a sua formação continuada na EPT.

Os cursos de curta duração para a qualificação profissional como é o caso do curso FIC em flexografia proposto, não são estudados e logo, não se encontra literatura a respeito do impacto desses cursos para a formação dos 
trabalhadores, tampouco o acompanhamento dos egressos. Um importante dado, que demonstra a efetividade do curso FIC para a formação profissional está registrado em depoimento do aluno $\mathrm{C}$, trabalhador do setor de processos de acabamento da fábrica de embalagens, afirmando que foi promovido para um cargo no setor do controle de qualidade da empresa, justamente por ter realizado o curso. Além disso, outros dois alunos comentaram abertamente aos professores no decorrer do curso terem conseguido uma ascensão funcional no seu trabalho correlacionada a frequentar o curso de flexografia. Mesmo na segunda turma ofertada, um dos alunos que encontrava-se desempregado durante o curso, após sua conclusão foi contratado para trabalhar numa empresa de impressão flexográfica devido à sua qualificação. Os cursos de curta duração, se bem estruturados e em consonância com o arranjo local, são uma importante ferramenta para as empresas qualificarem seus funcionários, mas o impacto desses cursos para a cidadania precisa ser melhor estudado para fortalecimento da permanência e êxito.

\section{CONSIDERAÇÕES FINAIS}

Através das estratégias metodológicas traçadas, realizou-se uma análise dos aspectos que envolvem a formação docente e a permanência e êxito. Propôs-se que, a capacitação por meios não formais de educação, é uma maneira eficaz de formação docente para a Educação Profissional e Tecnológica (EPT), a qual não tem sido considerada. As vantagens são: a possibilidade de personalização dos saberes a serem aprendidos em convergência com o contexto específico de atuação, a maior troca de conhecimentos entre o grupo docente fortalecendo as práticas pedagógicas interdisciplinares e a ação-reflexão crítica acerca do processo de ensinoaprendizagem. Dentro da formação docente continuada, um dos processos essenciais é a busca ativa, caracterizada pela aproximação entre a escola e as empresas. Isto leva a ampliação do acesso à qualificação dos trabalhadores, capacitação dos docentes para atuar efetivamente sobre a realidade laboral e atenuação da divisão entre as concepções da formação específica e da formação básica. Consequentemente, a troca de conhecimentos entre alunos e professores torna-se um fator diferencial tanto para a formação docente, quanto para o empoderamento discente. Logo, os resultados mostram que o processo de busca ativa é significativamente importante para o combate a evasão escolar.

Com base em tais resultados apresentados, aqui abordados como estudo de caso, faz-se primordial refletir sobre novas formas de organização da gestão escolar. O docente citado na discussão acima, ingressou num curso formal de especialização para EPT como caminho para a adequação profissional de acordo com as exigências legais. O sistema de ensino centralizado na burocracia exige a documentação, pois é formalizado após a ação processual, sendo esta a etapa mais importante para o cumprimento de tais exigências. No entanto, processos de educação não formais são desconsiderados neste caso. A burocracia não deve ser colocada à frente dos objetivos da ação pedagógica efetiva. Não obstante, o processo 
burocrático tem uma importante função regulamentadora e deve assumir um limiar básico fiscalizador. Porém, o sistema educacional não pode ser exclusivamente centralizado e burocrático. Novas formas de organização precisam ser aceitas e desenvolvidas, da mesma maneira que, a capacitação docente não formal pode ser considerada.

\begin{abstract}
A escola da liberdade e criatividade pressupõe alterações na forma e no conteúdo dos currículos escolares, assim como no processo de formação dos docentes, que não pode se resumir à aquisição de conhecimentos em domínios exclusivamente acadêmicos, mas deve-se adentrar no mundo das comunicações. Parte-se do suposto que o rendimento escolar deve-se, sobretudo, à qualidade das relações entre docentes e educandos. Ela requer ainda uma nova forma de gestão, não centrada exclusivamente no corpo técnico-burocrático-administrativo, mas envolvendo o conjunto dos setores. As soluções não devem ser impostas, mas negociadas publicamente. Isto pressupõe um sistema de comunicação composto sob a forma de redes, com canais bastante fluentes, com estruturas formais de representação em todos os níveis e segmentos (GOHN, 2011, p. 116).
\end{abstract}

As escolas são governadas por índices que visam otimizar a quantidade de alunos matriculados em função do número de servidores e da sua estrutura física. Por conseguinte, na gestão escolar centralizada gera-se um efeito cascata, pressionando-se cada vez o aumento da carga horária dos professores em sala de aula, voltado exclusivamente ao ensino. Entretanto, há um grande conflito entre esta forma de gestão e os ineficientes paradigmas da educação profissional, o qual precisa ser adequado se, deseja-se uma educação emancipadora, cidadã, integral e transformadora das desigualdades numa perspectiva de humanização do trabalho.

A relação conflituosa entre ensino, pesquisa e extensão dificulta a tomada de ações para uma educação mais eficaz para o trabalhador. A pequena carga horária disponível para a realização de extensão e pesquisa pelos docentes na escola técnica prejudica diretamente a formação docente, sendo que, o professor precisa ter um diálogo constante com as empresas, com os trabalhadores e com a sociedade. Ações de extensão tomam um grande tempo da carga horária de trabalho, o que, considerando a elevada carga horária de ensino, sobrecarrega as atividades docentes enfraquecendo o processo de formação continuada. Sobretudo, é indispensável que a prática docente seja fundamentada pela pesquisa. Aquele que não pesquisa a própria prática, não gera conhecimento, sendo então, um simples reprodutor de práticas educacionais e sociais as quais não condizem com a realidade local e, portanto, não são transformadoras. É urgente que se coloque em prática o princípio da indissociabilidade entre ensino, pesquisa e extensão, inovando a organização do trabalho docente e da gestão escolar, a fim de combater os aspectos ineficazes da EPT, e talvez, amenizar-se o crítico problema da evasão e retenção escolar. 


\section{REFERÊNCIAS}

ARROYO, M. G. A Pedagogias em movimento: o que temos a aprender dos movimentos sociais. Currículo sem Fronteiras, v. 3, n. 1, p. 28-49, 2003.

\section{BAZZO, W. A. Ciência, Tecnologia e Sociedade e o Contexto da}

Educação Tecnológica. Florianópolis: EDUFSC, 2015.

CAMPOS, A. T.; et al. Os Saberes Docentes para a formação de professores da Educação Profissional e Tecnológica. Educitec, n. 01, p. 01-09, 2018.

CARVALHO, O. F. Educação e Formação Profissional: Trabalho e tempo livre. Brasília: Plano Editora, 2003.

CORTESÃO, L.; TORRES, M. A. Avaliação Pedagógica I: Insucesso Escolar. 4 ed. Porto: Porto Editora, 1990.

DA SILVA, K. K. O.; QUEIROZ, K. S.; MEDEIROS, S. M. D. Trabalho e trabalho docente: a percepção de docentes da área de formação geral. Revista Brasileira de Educação Profissional e Tecnológica, v.1, n. 12, p. 7081, 2017.

DORE, R. Evasão na educação: estudos, políticas e propostas de enfrentamento. Brasília: IFB, 2014.

DORE, R.; LÜSCHER, A. Z. Permanência e evasão na educação técnica de nível médio em minas gerais. Cadernos de Pesquisa, v. 41, p. 772-789, 2011.

EMERSON, R. M.; FRETZ, R. I.; SHAW, L. L. Writing ethnographic fieldnotes. Chicago: University of Chicago Press, 1995.

FAZENDA, I. O que é interdisciplinaridade? São Paulo:Cortez, 2008.

FONSECA, C. M. F. Formação e saberes docentes na educação profissional: um relato de experiência. Revista Brasileira de Educação Profissional e Tecnológica, v.1, n. 12, p. 170-178, 2017.

FORQUIN, J. Sociologia da Educação. Petrópolis: Vozes, 1995.

FRANCO, M. C. A formação de professores para a Educação Profissional e Tecnológica: perspectiva histórica e desafios contemporâneos. In: Educação Superior em Debate, v. 8. Brasília: Instituto Nacional de Estudos e Pesquisas Educacionais Anísio Teixeira, 2008.

FRIGOTTO, G. A formação e profissionalização do educador: novos desafios. In: SILVA, T. T.; GENTILI, P. Escola S.A.Brasília: da CNTE, 1996, p. 75-105.

GALLINDO, E. Análise Evasão de Rede Federal de Educação Profissional e Tecnológica, 2018. Disponível em: $<$ https://public.tableau.com/profile/ericagallindo\#!/vizhome/2017-0218AnliseEvasoRF/Painel1>. Acesso em: fev. 2018 
GARIGLIO, J. A.; BURNIER, S. Saberes da docência na educação profissional e tecnológica: um estudo sobre o olhar dos professores. Educação em Revista, v. 28, n. 1, p. 211-236, 2012.

GIANNASI, M. J.; BERBEL, N. A. N. Metodologia da problematização como alternativa para o desenvolvimento do pensamento crítico em cursos de educação continuada e à distância. Informação \& Informação, v. 3, p. 19-30, 1998.

GERHARDT, T. E.; SILVEIRA, D. T. Métodos de pesquisa. Porto Alegre: Editora da UFRGS, 2009.

GOHN, M. G. Educação não formal e cultura política: impactos sobre o associativismo do terceiro setor. 5 ed. São Paulo: Cortez, 2011.

HENRIQUE, A. L. S.; et al. Dossiê docência na educação profissional. Revista Brasileira de Educação Profissional e Tecnológica, v. 1, n. 12, p. 1-5, 2017.

IMBERNÓN, F. Formação Docente e Profissional: formar-se para a mudança e a incerteza. 9. ed. São Paulo: Cortez, 2011.

INSTITUTO FEDERAL DE SANTA CATARINA. Plano de Desenvolvimento Institucional 2015-2019. Florianópolis, 2015.

INSTITUTO FEDERAL DE SANTA CATARINA. Anuário Estatístico IFSC. Florianópolis, 2017.

INSTITUTO FEDERAL DE SANTA CATARINA. Plano estratégico de permanência e êxito dos estudantes do IFSC. Florianópolis, 2018.

KUENZER, A. Z. As políticas de educação profissional: uma reflexão necessária. In: MOLL, J. Educação profissional e tecnológica no Brasil contemporâneo: desafios, tensões e possibilidades. Porto Alegre: Artmed, 2010.

KUENZER, A. Z. A formação de professores para o Ensino Médio: velhos problemas, novos desafios. Educação e Sociedade, v. 32, n. 116, p. 667688, 2011.

MACHADO, L. R. S. Diferenciais inovadores na formação de professores para a educação profissional. Revista Brasileira de Educação Profissional e Tecnológica, v. 1, n. 1, p. 8-21, 2008.

MCNEAL, R. B. Parental involvement as social capital: differential effectiveness on science achievement, truancy and dropping out. Social Forces, n. 78, p. 117-144, 1999.

MOTTA, T. C.; CAVALCANTE, I. F.; LEMOS, E. Política de extensão na perspectiva colaborativa pela formação docente. Revista Brasileira de Educação Profissional e Tecnológica, v. 1, p. 1-17, 2018.

MOURA, D. H.; GARCIA, S. R. O.; RAMOS, M. N. Educação profissional técnica de nível médio integrada ao ensino médio: documento base. Brasília: Ministério da educação, 2007. 
MOURA, H. D. A formação docente para a educação profissional e tecnológica. Revista Brasileira de Educação Profissional e Tecnológica, v. 1 , n. 1, p. 23-37, 2008.

NASCIMENTO, E.; et al. O processo de formação inicial e continuada dos trabalhadores na área de flexografia: os aspectos socioeconômicos e o ensino profissional. Educitec, v. 04, n. 08, p. 340-356, 2018.

NASCIMENTO, E. D. A.; SOUZA, A. C. R.; OLIVEIRA, S. A. B. Reflexões sobre a mudança de paradigmas no ensino tecnológico. Educitec, v. 04, n. 07, p. 11-18, 2018.

NÓVOA, A. Formação de Professores e Profissão Docente, 1991. Disponível em: <http://core.ac.uk>, Acesso em: jan. 2018

PEREIRA, T. C. B.; PASSOS, G. O. Avaliação da política de assistência estudantil na educação profissional de nível técnico: análise dos indicadores da evasão e retenção no IFPI Câmpus Teresina Central. Cadernos de Educação, v. 57, p. 80-92, 2017.

PINTO, A. B. M.; DELGADO, J. P. F.; MARTINS, A. M. O. Significados e perspectivas do insucesso escolar no ensino profissional em Portugal. Cadernos de Educação, n. 51, p. 1-21, 2015.

RAMOS, M.; FRIGOTTO, G.; CIAVATTA, M. Ensino médio integrado: Concepção e contradições. São Paulo: Cortez, 2005.

RODRIGUES, J. Celso Suckow da Fonseca e a sua "história do ensino industrial no Brasil”. Revista Brasileira de História da Educação, n. 4, p. 4774, 2002.

RODRIGUES, M.R.S.L.; FREITAS, M.C.S. Formar-se para ensinar: experiência de um Instituto Federal. Revista Brasileira de Educação Profissional e Tecnológica, v. 2 , n. 11, p. 51-70, 2016.

RUMBERGER, R. Dropping out of middle school: a multilevel analysis of students and schools. American Educational Research Journal, v. 32, n. 4, p. 583-625, 1995.

SANTOMÉ, J. T. Globalização e interdisciplinaridade: o currículo integrado. Porto Alegre: Artes Médicas, 1998.

SANTOS, A. S.; AZEVEDO, R. O. M.; GONZAGA, A. M. Tendência dos Saberes na formação profissional do professor: um olhar a partir do ensino tecnológico. Educitec, n. 02, p. 01-08, 2015.

SAVIANI, D. Formação de Professores no Brasil: Dilemas e Perspectivas. Revista Poíesis Pedagógica, v. 9, n. 1, p. 07-19, 2011.

SCARPETA, E. Flexografia: Manual Prático. São Paulo: Bloco Comunicação Ltda, 2007.

SIL, V. Alunos em Situação de Insucesso Escolar. Lisboa: Horizontes Pedagógicos, 2004.

SILVEIRA; R. B.; GONÇALVES, L. F.; MARASCHIN, M. S. A formação de professores na educação profissional e tecnológica e a complexidade 
que envolve a permanência e êxito dos estudantes. Revista Brasileira da Educação Profissional e Tecnológica, v. 2, n. 13, p. 81-93, 2017.

SOARES, J. O efeito da escola no desempenho cognitivo dos alunos. Revista Electrónica Iberoamericana sobre Calidad, Eficácia y Cambio en Educación, v. 2, p. 83-104, 2008.

TARDIF, M. Saberes docentes e formação profissional. 16 ed. Rio de Janeiro: Vozes, 2014.

TAVARES, A. N.; GONZAGA, A. M. Currículo, transdisciplinaridade e educação tecnológica: articulando concepções na perspectiva do Terceiro Incluído na Formação de Professores. Educitec, n.04, p. 01-12, 2016.

TEACHMAN, J. D.; PEASCH, K.; CARVER, K. Social capital and dropping out of school early. Journal of Marriage and the Family, v. 58, n. 3, p. 773783, 1996.

TEDDLIE, C.; REYNOLDS, D. The International handbook of school effectiveness research. Nova York: Falmer Press, 2000.

TORRES, I. C.; SILVA, J. L.; ALVES, F. M. D. Alfabetização científica e tecnológica: uma necessidade à formação docente. Educitec, n. 06, p. 4250, 2017.

TOUTKOUSHIAN, R.; CURTIS, T. The effects of socioeconomic factors on public high school outcomes and rankings: Evidence from New Hampshire. Journal of Educational Research, v. 98, p. 259-271, 2005.

VIANNA, H.M. Pesquisa em educação: a observação. Brasília: Plano Editora, 2003.

VIEIRA, M.M.M.; VIEIRA, J.A.; PASQUALLI, R. Formação de professores da educação profissional nos programas especiais de formação pedagógica. Revista Brasileira da Educação Profissional e Tecnológica, v. 1, n. 7, p. 43-55, 2014. 